\title{
Ultralight Stainless Steel Urban Bus Concept
}

\author{
J. Bruce Emmons and Leonard J. Blessing \\ Autokinetics Inc
}

Permission is hereby granted for a copyright release fee of $\$ 300$ per paper. An invoice will follow under separate cover. Please be sure to include the following credit statement with these papers:

"C Society of Automotive Engineers, Inc. The following papers are published on this web-site with permission from the Society of Automotive Engineers, Inc. As a user of this web-site, you are permitted to view these papers on-line, download the PDF file and to print a copy at no cost for your use only. Dowloaded PDF files and printouts of SAE papers contained on this web-site may not be copied or distributed to others or for the use of others." 
The appearance of this ISSN code at the bottom of this page indicates SAE'S consent that copies of the paper may be made for personal or internal use of specific clients. This consent is given on the condition, however, that the copier pay a $\$ 7.00$ per article copy fee through the Copyright Clearance Center, Inc. Operations Center, 222 Rosewood Drive, Danvers, MA 01923 for copying beyond that permitted by Sections 107 or 108 of the U.S. Copyright Law. This consent does not extend to other kinds of copying such as copying for general distribution, for advertising or promotional purposes, for creating new collective works, or for resale.

SAE routinely stocks printed papers for a period of three years following date of publication. Direct your orders to SAE Customer Sales and Satisfaction Department.

Quantity reprint rates can be obtained from the Customer Sales and Satisfaction Department.

To request permission to reprint a technical paper or permission to use copyrighted SAE publications in other works, contact the SAE Publications Group.

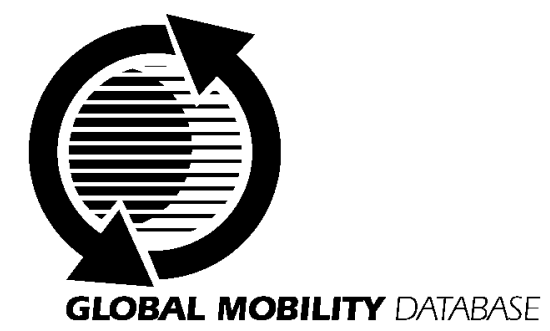

All SAE papers, standards, and selected books are abstracted and indexed in the Global Mobility Database

No part of this publication may be reproduced in any form, in an electronic retrieval system or otherwise, without the prior written permission of the publisher.

ISSN 0148-7191

Copyright 2001 Society of Automotive Engineers, Inc.

Positions and opinions advanced in this paper are those of the author(s) and not necessarily those of SAE. The author is solely responsible for the content of the paper. A process is available by which discussions will be printed with the paper if it is published in SAE Transactions. For permission to publish this paper in full or in part, contact the SAE Publications Group.

Persons wishing to submit papers to be considered for presentation or publication through SAE should send the manuscript or a 300 word abstract of a proposed manuscript to: Secretary, Engineering Meetings Board, SAE.

\section{Printed in USA}




\title{
Ultralight Stainless Steel Urban Bus Concept
}

\author{
J. Bruce Emmons and Leonard J. Blessing \\ Autokinetics Inc
}

Copyright @ 2001 Society of Automotive Engineers, Inc.

\begin{abstract}
While stainless steel buses are certainly not new, this study reveals opportunities for substantial improvements in structural performance. The objective of this project was to investigate the mass saving potential of ultra-high strength stainless steel as applied to the structure of a full size urban transit bus. The resulting design for a low floor, hybrid bus has an empty weight less than half that of a conventional transit bus. The reduced curb weight allows for a greater payload, without exceeding legal axle limits. A combination of finite element modeling and dynamic testing of scale models was used to predict structural performance.
\end{abstract}

\section{INTRODUCTION}

Advanced technology transit bus concepts such as the ATTB have made significant advancements in terms of light weight and fuel economy. However, these gains have come at the expense of higher manufacturing costs (1). In spite of attempts to use life-cycle costs to justify their purchase, initial cost remains a major obstacle to the introduction of fuel-efficient buses.

Autokinetics was approached by the Office of Heavy Vehicle Technologies of the US Department of Energy to attempt to solve this problem. Specifically, the OHVT asked Autokinetics to develop concepts for a lightweight urban transit bus based on the use of high-strength stainless steel. In the passenger car field, Autokinetics had developed structural and manufacturing techniques for the cost-effective use of stainless steel in spaceframes and suspensions. The OHVT asked if this approach could be applied to transit buses as well.

The program was structured to have three phases:

- Phase I - Initial Concept Development

- Phase II - Concept Verification and Initial Design

- Phase III - Final Design and Prototyping of Body and Chassis
At this point in time, Phase I and Phase II have been successfully completed. It is expected that Phase III will begin in the near future, and will be completed in about 12 months. Phase III will result in a full size body structure and suspension that will be tested statically and dynamically. The development of a hybrid powertrain and other vehicle systems will be performed in Phase IV.

This project was unusual in that no formal mass or cost targets were given. The object was to save as much mass and cost as possible.

\section{DESIGN APPROACH}

In developing the structural concept for the bus, a twostaged design approach was followed:

1. Start with an inherently stiff design concept - By qualitatively examining the loading conditions and the packaging requirements, concepts were developed that fully constrained the internal degrees of freedom of the structure with a complete system of load paths. This approach resulted in a structural geometry of unusually high stiffness for a given mass.

2. Use material with high specific strength to save mass - The qualitative load path geometry was quantified using finite element analysis. Since stiffness requirements were already addressed, the bus structure mass was dictated by strength requirements. By choosing a material with a high specific strength, such as tensilized stainless steel, significant mass reductions could then be achieved.

The separation of qualitative design issues from quantitative analysis issues allowed the concept development process to proceed in an orderly fashion without resorting to trial and error methods. 


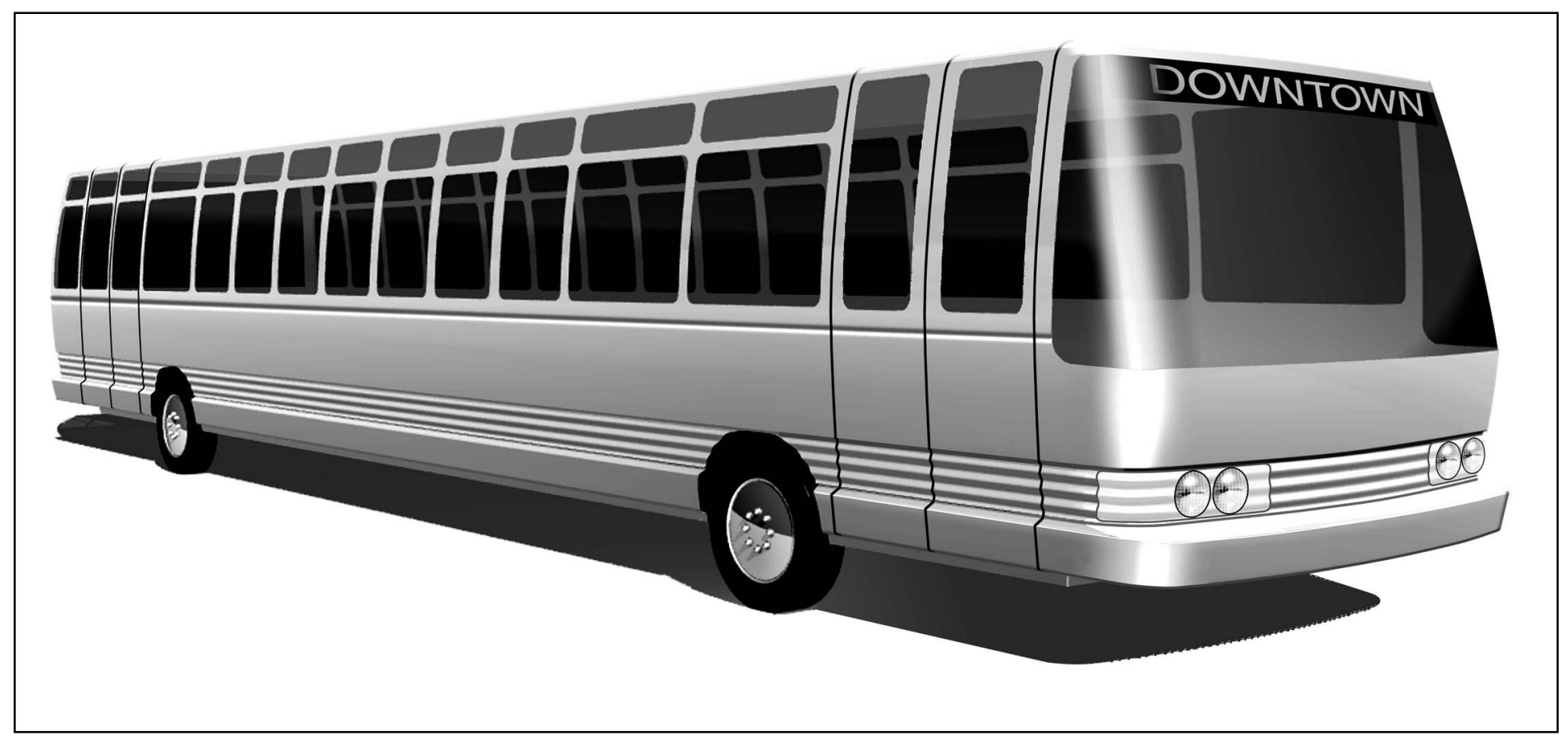

Figure 1 - Ultralight Urban Bus

\section{DESIGN DESCRIPTION}

As the project became defined, the ultralight stainless steel bus concept was aimed at the typical city transit bus. It was configured as a low floor, full size ( $40 \mathrm{ft}$ ), urban transit bus, utilizing a monocoque type structure (see Figure 1). Although the primary emphasis was mass savings, it was also necessary to address ridership and fleet operator issues. Because of the monocoque nature of the structure, and in order to ensure a realistic design, a comprehensive vehicle architecture was defined. The basic architecture was planned around the following goals:

- Mass reduction - improved fuel efficiency;

- Minimize cost (purchase, operation, life cycle);

- Improved performance, usability, comfort.

It was determined that a "low floor" configuration, preferably a single level (no step) floor, was desirable to facilitate improved passenger capacity, flow patterns, and usability. Other features of the basic vehicle architecture were selected, in part, for their inherent synergistic compatibility with a low floor configuration. For example, the monocoque type structure allows a low floor height while maintaining ground clearance and providing a very efficient structure. Likewise, the fourwheel independent suspension required no interior intrusion for axle clearance while providing the opportunity for improved ride and handling. The hybrid powertrain, in addition to reducing overall mass and fuel consumption, also minimized interior intrusion, and enabled the repositioning of the powertrain under the rear seat. With a good understanding of the basic vehicle architecture and its requirements, the detail design of the body structure proceeded.

BODY STRUCTURE - The stainless steel body structure concept is shown in Figure 2. The monocoque type body structure was conceptually viewed as a six-sided box. Using this model as a basis, the sides of the "box" were configured according to their individual requirements. Some key features are discussed here.

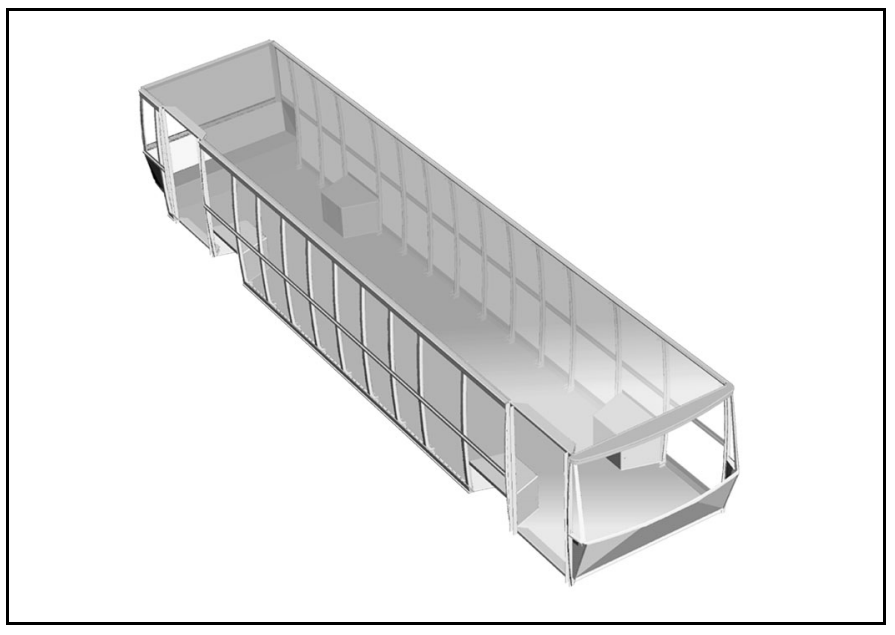

Figure 2 - Body structure

Roof and floor panels - For a full low-floor bus configuration, it is important to keep the total thickness of the floor structure as thin as possible. This is to achieve the lowest possible step-up height while maintaining adequate ground clearance. The structural requirements are to support a distributed load equal to 2.5 times the maximum passenger load, and to have panel resonant frequencies high enough for good $\mathrm{NVH}$ qualities. To 
meet these requirements, it was decided to use a onepiece spot-welded sandwich panel constructed of two flat outer sheets and one "corrugated" shaped inner sheet. The roll-formed corrugations are oriented to run laterally across the vehicle. The outer face sheets are .050" thick, while the inner corrugated sheet is .030" thick.

It was also decided to use this type of construction for the roof panel. This allows for convenient and versatile support for roof mounted components such as HVAC, fuel cylinders, and hybrid power components. The roof panel is similar to the floor except that the outer face sheets are $.030 "$ thick.

Sidewalls - Constant channel-section pillars span between the roof and floor panels. The pillars were specifically designed to be easily roll-formed with a continuous curvature. The pillars were generally spaced in alignment with the seating pitch (28 inches). This enabled cantilevered seats mounted directly to the pillars and an individual window layout. Joining of the pillars to the roof/floor panels was accomplished through the arrangement of simple brackets (see Figure 3). The design of the joints, in conjunction with the lateral orientation of the roof/floor panel corrugations, provides moment-carrying ability to the cross-section. This is important to resist lateral match-boxing and panel "breathing" along the mid-span of the bus. Constantsection, roll-formed corner reinforcement rails were designed to provide surface and sealing continuity between the roof/floor panels and the side surfaces. Additionally, the lower reinforcement rail was configured to enhance impact protection by distributing loads into the pillars and performing the function of an intrusion barrier. The outer side panels and fixed glazing, attached to the pillars and reinforcement rails, provide shear continuity to the sidewalls. An upper row of windows was designed to be operational for ventilation. Additional openings were incorporated in the sidewalls to accommodate doors and emergency exits. They are discussed later in this section.

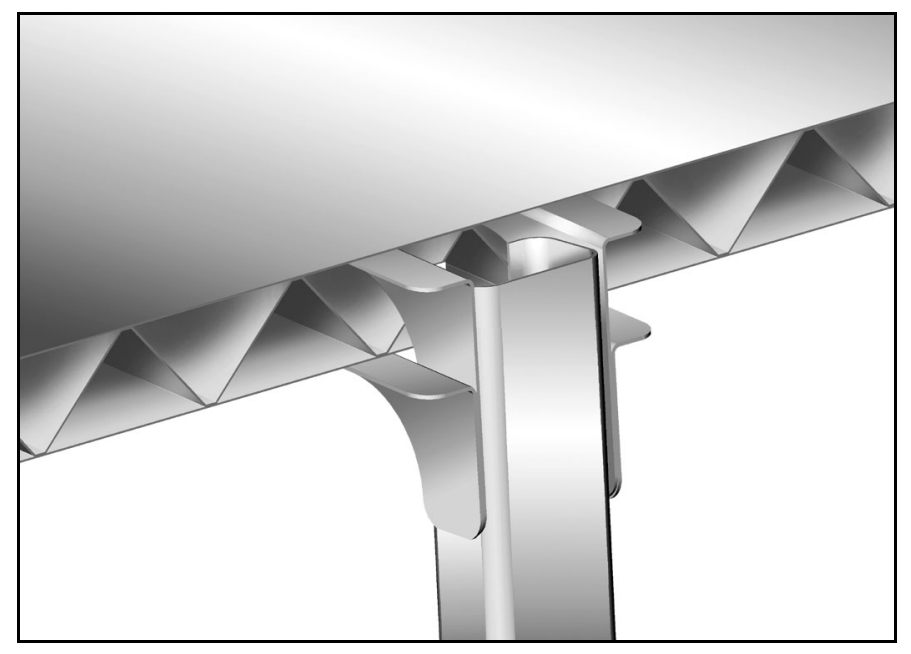

Figure 3 - Pillar joint detail
Front and rear end caps - Non-visual close-out panels consisting of the seat surround (rear), and dash panel (front) were designed to incorporate the necessary shear paths at the ends of the bus. Care was taken to ensure joining of these panels was such that the spot-welds are loaded in shear. Again, glazing, bonded in place with a urethane adhesive, was used to provide shear continuity to these sides of the box.

Structural wheelhouses - The integrated structural wheelhouses were designed to carry and distribute the suspension input loads into the overall body structure. Two channel brackets in each wheelhouse provide all necessary suspension mounting points. A pair of simple roll-formed cross-members (per axle) connects the suspension attachment brackets laterally. It was conceived that this arrangement might be subassembled and included in a pre-assembled axle module including suspension, wheel motors, brakes, and steering.

Door-frames - Body side openings for doors and emergency exits had to be accommodated. Generally, such openings interrupt shear continuity causing stress concentrations and local deformations which diminish overall structural integrity. This problem was addressed by designing structural hoops around the perimeter to provide diagonal stiffness across the openings. In the case of door openings, heavy gage roll-formed channels form such a hoop by overlapping the corners and attaching back-to-back. The header and threshold portions of the hoop are gloved over and welded to the roof and floor panels respectively (see Figure 4). In the case of emergency exits, the diagonal stiffness is provided by a subassembly consisting of a stainless steel frame to which glazing is bonded. The stainless steel frame incorporates an interface for locating and securing it into the body opening. Although door closures were not thoroughly investigated, the dooropening hoop was designed to accommodate a fairly conventional door system.

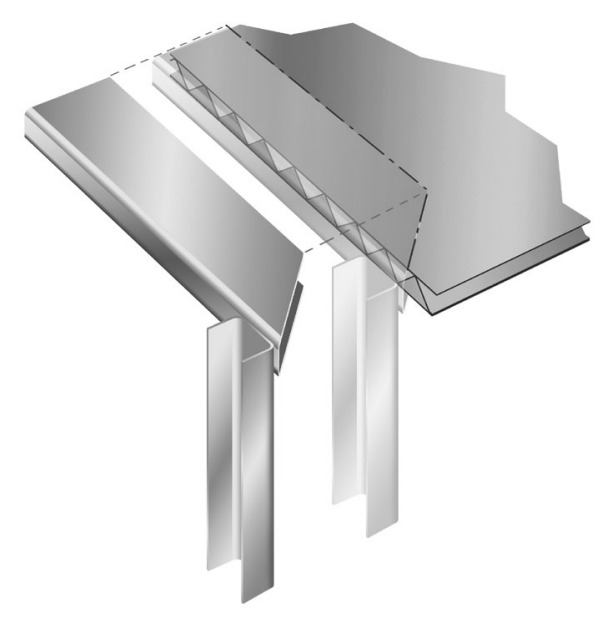

Figure 4 - Door-frame detail 
SUB-SYSTEMS - Though the body structure was the primary focus of this project, many of the subsystems where investigated to a level sufficient to assure compatibility with the body concept. In most cases, compounding benefits were realized by a systems design approach.

Powertrain - The powertrain was viewed as a hybrid, consisting of a power generation source (engine turning a generator) and a power transmission/delivery device (wheel-mounted electric motors). This approach offered two principal benefits. First, the hybrid approach offered the potential for greater energy efficiency as well as cleaner, quieter operation. Second, without the requirement for a mechanical connection between the power generation source and the driven wheel, a completely flat floor throughout the bus was maintained, achieving maximum passenger capacity. Additionally it allows for multiple options for engine type and placement.

Power generation source - By the nature of a hybrid powertrain, the vehicle structure design is not particularly dependent upon the specific characteristics of any given power generator. This allows multiple options in the selection of the power generation source. For the purposes of developing the design, a system was chosen which consisted of two small displacement inline four-cylinder engines, each coupled to a generator, and fueled by compressed natural gas. Some optional power generation sources were identified including gas turbine/generator, external power pickup lines, and fuel cells.

Power transmission/delivery device - Permanent magnet wheel motors were incorporated to drive the rear wheels through a gear reduction unit. Additionally, these motors increase energy efficiency through regenerative braking.

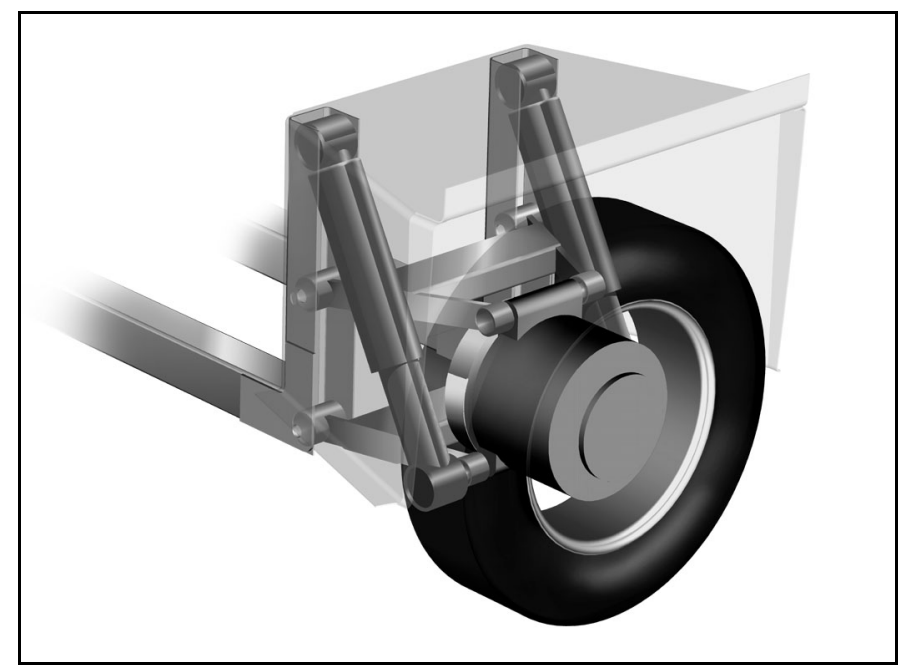

Figure 5 - Rear suspension concept

Suspension - Preliminary designs for independent front and rear suspensions were generated and integrated into the structure design. The front uses a typical steering knuckle, which carries the wheel hub, brakes, and steering links. The rear wheel hub was integrated into a gear reduction unit, to which the wheel motor is also mounted (see Figure 5). Both front and rear suspensions employ hydro-pneumatic springs to compensate for the wide disparity between unloaded and loaded vehicle weight. The spring system consists of a cylinder and accumulator located in the wheelhouse while the hydraulic pump is remotely located. The independent front and rear suspensions also contribute to maintaining a completely flat floor design as well as a lower overall mass. Also note-worthy; the projected GVW of $24,000 \mathrm{lbs}$ allowed the use of a single 21575/R17 conventional truck tire at each corner. With the relatively small overall tire diameter, wheel travel was increased to \pm 4 inches and the wheelhouses were reduced enough in size to allow seating above. This greatly enhanced the capacity and usability of the bus.

Seating - Because the seating can contribute a significant amount of weight, as well as influence overall dynamics, a compatible seating concept was developed. As shown in Figure 6, a cantilevered seat was designed to be constructed of two horizontal beams attached to the body pillars. These beams form the top edge of the seat back and the front edge of the seat cushion. "L" shaped braces on the ends tie the beams together. A stainless steel expanded metal mesh or perforated sheet forms the seating surface. This configuration should prove to be relatively inexpensive, lightweight, and comfortable, yet impervious to soiling and virtually indestructible.

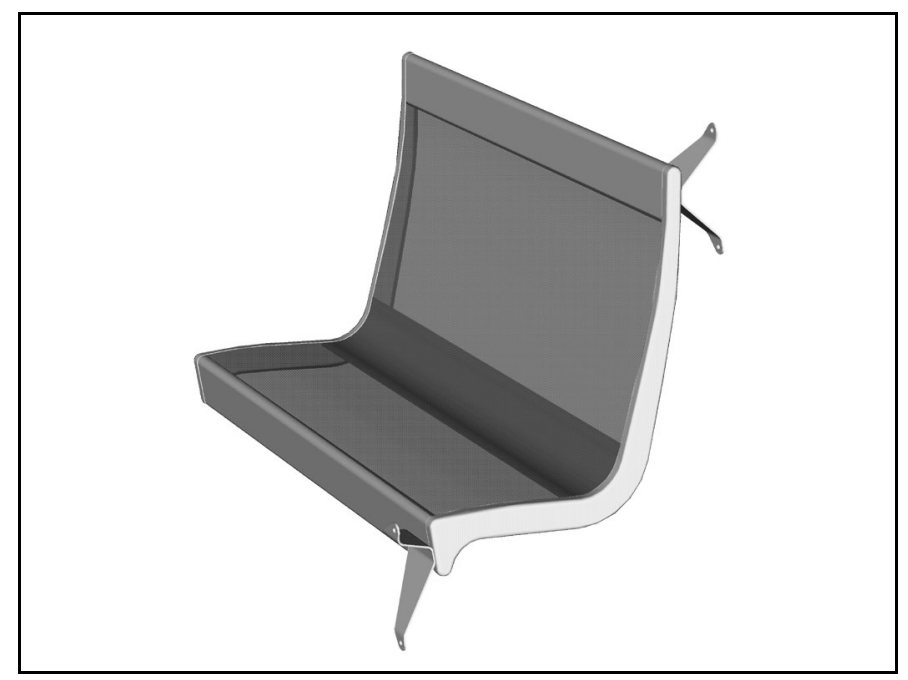

Figure 6 - Seat concept

HVAC - A roof mounted, self-contained HVAC unit was selected to simplify manufacture and maintenance. With this approach the HVAC unit has little impact on the structural design, other than the need for adequate mounting provisions. 
Fuel system - As with the power generator, multiple options for fuel type exist. Specific fuel system requirements are, of course unique to the choice of fuel type. Various fuels were investigated to ensure the structure would comprehend storage volumes and locations, as may be required. Again, for illustration purposes, this concept was developed as a natural gas fueled vehicle. For this particular system, multiple fuel cylinders were located on the roof. The combined capacity was equivalent to about 50 gallons, providing a range of approximately 300 miles. A cover was conceived to protect and conceal the fuel system and roof mounted accessories as well as smooth aerodynamic flow and shed precipitation and debris.

Crash management - A system of consumable members, which absorb energy in a crash event, was integrated into the design. Energy absorption is accomplished by axially loading tubular members fitted with special forming caps (see Figure 7). As the forming caps are driven into the tubes, the tubing walls are elastically formed inverting the tube on itself. These energy-absorbing members are attached to substantial cross members, which distribute the loads into the floor.

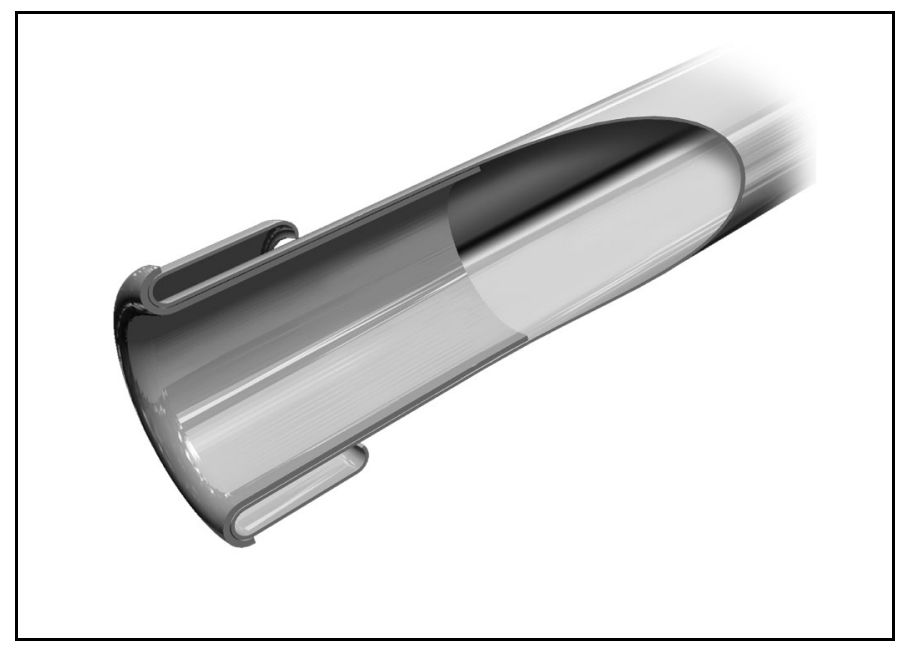

Figure 7 - Energy absorber concept

\section{MATERIALS}

The material that was chosen for the structure of the Ultralight Urban Bus is Nitronic 30 (4), produced by AK Steel. This is a nitrogen strengthened, austenitic stainless steel. In this application, it is being used in a tensilized form, achieved by cold-rolling the sheet without a final anneal. There is considerable freedom on the part of the designer to specify the mechanical properties required by the application. In this case, a yield strength of 120,000 psi was specified, with a resulting elongation of about $25 \%$. This is a remarkable combination of high strength and ductility for any material. There is, of course a trade-off between strength and ductility. The greater the amount of cold-rolling, the higher the yield strength, but the lower the ductility. This relationship can be seen in Figure 8.
Nitronic 30 has excellent fatigue properties, with an endurance limit of $70 \mathrm{ksi}$ for annealed material. The endurance limit for cold-worked material will be higher. A $\mathrm{S} / \mathrm{N}$ curve is given in Figure 9.

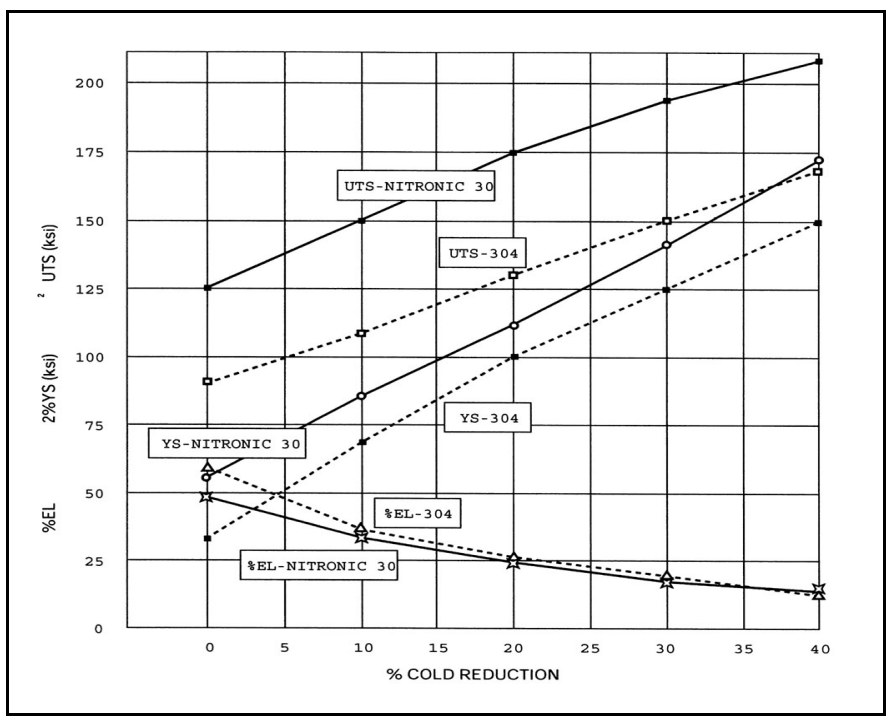

Figure 8 - Properties of Nitronic 30 as a function of cold reduction (source AK Steel) (4)

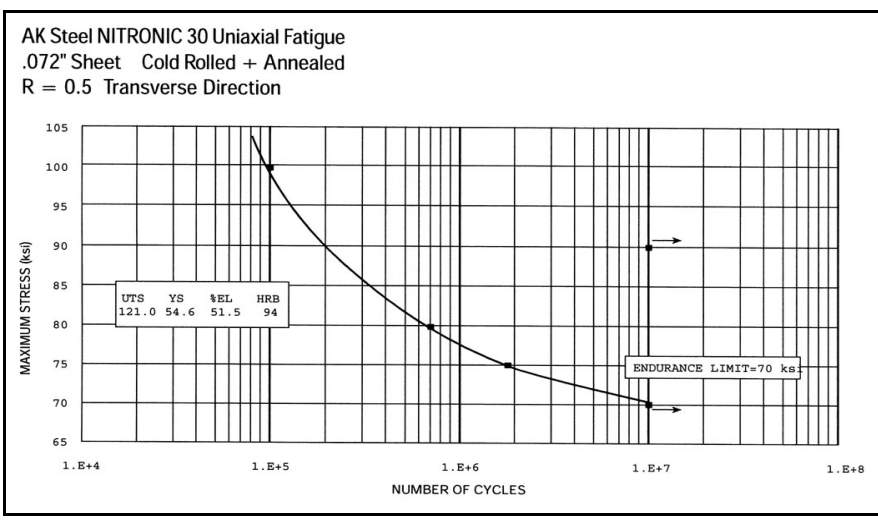

Figure 9 - Fatigue properties of Nitronic 30 (source AK Steel) (4)

\section{MANUFACTURING}

An important constraint on the structural concept development process was to limit the design to simple, low cost manufacturing processes. Because bus manufacturing is always a low volume operation, it is also important to minimize the investment required. The principle forming process that was used is contour rollforming. This is a well-known process in which a coil of material is fed through a series of progressively shaped rollers (see Figure 10). After the section profile is formed, the finished part is sheared to length by a flying shear. This process is particularly well suited for the use of high strength materials because the shape is created primarily by bending, rather than by stretching or drawing the material. By offsetting the final stage of rollers, it is possible to roll a constant radius curvature into the part. This technique has been used for the side pillars. Roll- 
forming was also chosen to produce the corrugated cores for the floor and roof panels. While this approach is a bit less structurally efficient than honeycomb core, it is vastly more cost-effective.

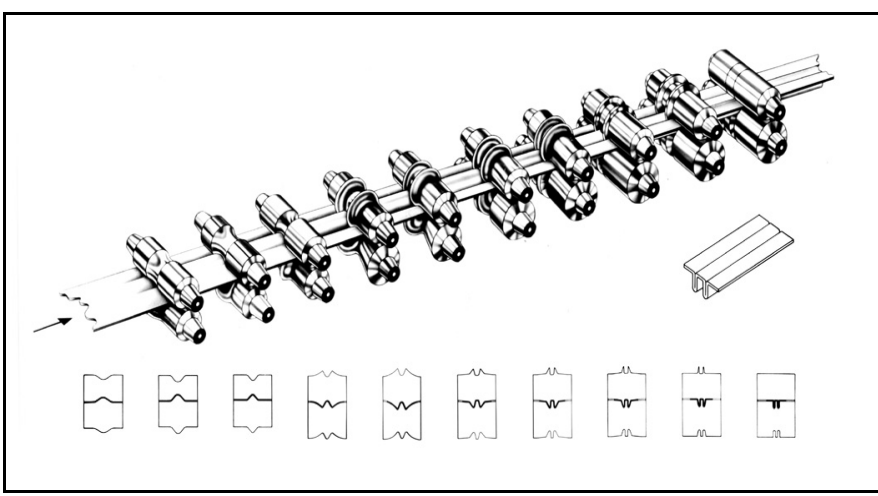

Figure 10 - The Roll-forming process (source Sawhill Tubular Division of AK Steel)

The major joining process is spot-welding. This process is extremely common in passenger cars and light trucks, but is less typically used in bus manufacturing. Fortunately, Nitronic 30 has properties that are highly compatible with spot-welding. Its low electrical and thermal conductivity make it easy to generate resistance heating, and to keep it localized. The weld, and the heat-affected zone retain most of their original strength without any brittleness. Also, there are no coatings to contaminate the weld.

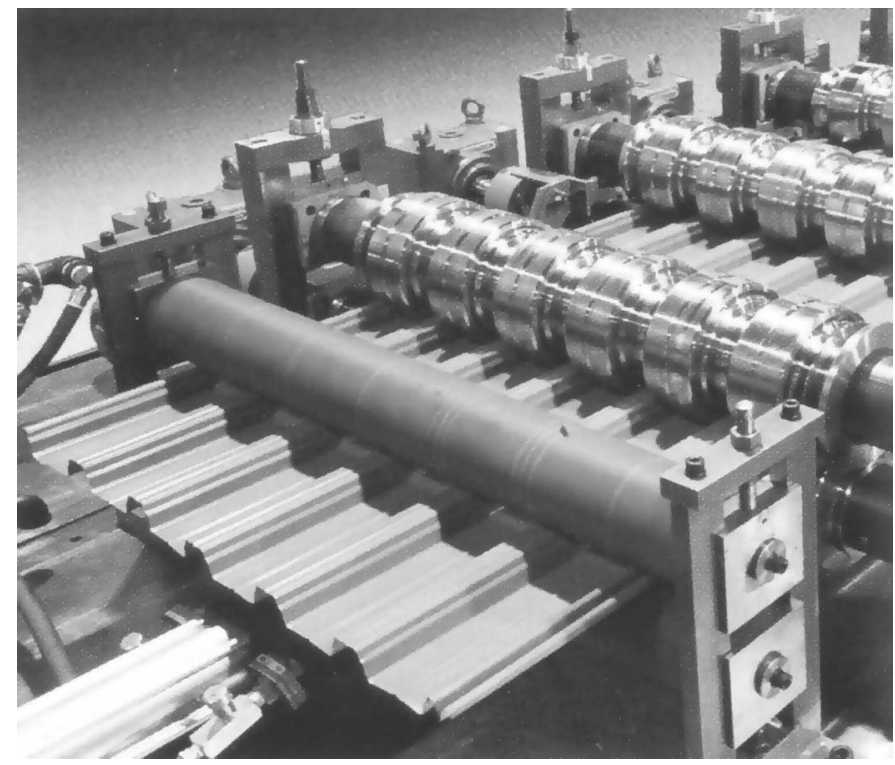

Figure 11 - Roll-forming of typical corrugated panel (source SAMCO)

The floor and roof sandwich panels use a combination of roll-forming and spot-welding in their construction. This form of panel construction has been used before for Navy ship decks and aerospace applications, but only in very low volumes. The roll-forming of corrugated stainless steel sheets is commonly done for roofing and bridge decking (see Figure 11). A new set of tooling is all that would be required for this bus application.

The joint between side pillars and floor (or roof) was designed not only for structural efficiency, but also to allow simple manufacturing. Spot-welding is used in place of more labor intensive MIG welding.

\section{DESIGN VALIDATION}

With the structural design concept well established, a number of finite element models were created in order to quantify the material gages, and to study various aspects of the structural design.

HALF BUS MODEL - In the early stages of concept development, a simple beam and shell element model was used to guide the design process. See Figure 12. This model was a half model that assumed lateral symmetry. From this model, it was learned that the door openings play a critical role in the overall stiffness of the bus. Unfortunately, because of the nature of the symmetry assumption, the bus model behaved as if it had doors on both sides. This was not a problem in the early concept development phase, but it was decided to go to a full bus model for validation of the design concept.

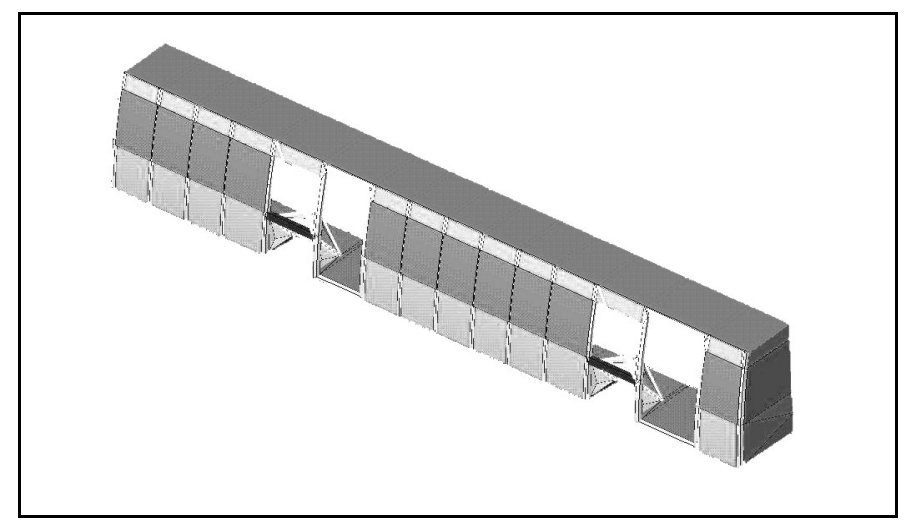

Figure 12 - Half model of bus concept

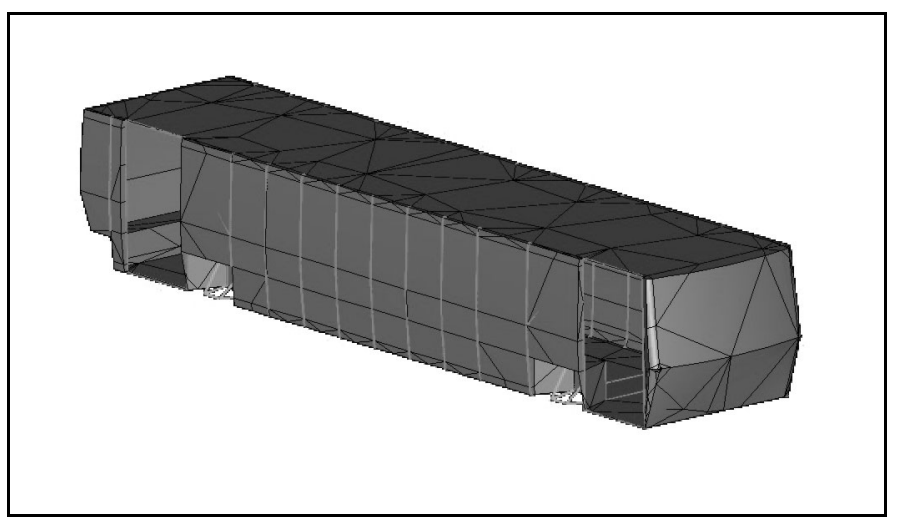

Figure 13 - Full bus FEA model

FULL BUS MODEL - As the design concept progressed, a more detailed model of the bus was constructed as is 
shown in Figure 13. This was a full model of the bus structure, so it was possible to represent having two doors on one side of the bus, and none on the other side.

Model Details - The finite element model was built and analyzed using PTC Pro-MECHANICA software. Since Pro-MECHANICA uses high-order p-elements, the element mesh can be relatively coarse without affecting the accuracy of the results. To limit the complexity of the model, beam elements were used to represent long, rollformed sections such as the pillars, corner reinforcement rails, door frames, and suspension attachment structures (see Figure 14).

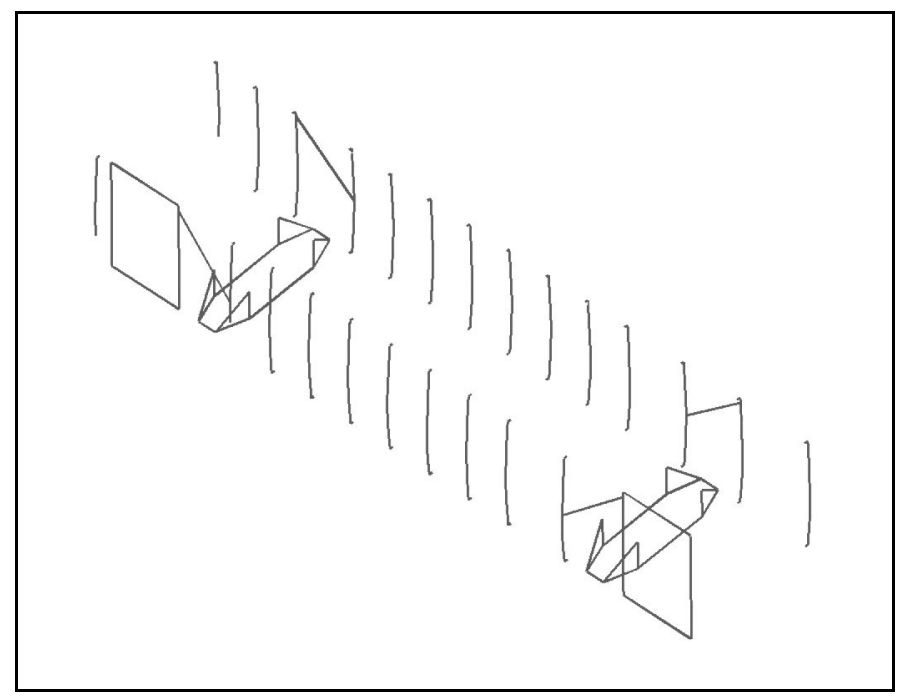

Figure 14 - FEA beam elements

Shell elements were used for the rest of the bus structure. Special properties were assigned to the floor and window shell elements, as described in the sections below. For analysis of natural frequencies and mode shapes, the model was unconstrained. This was a dynamic analysis of the structure only; other components such as the powertrain were not included in the model. Load cases were developed to ensure compliance with structural integrity tests conducted at the Federal Bus Testing Facility in Altoona, PA. These test cases are described in the APTA "Standard Bus Procurement Guidelines"(2) and in 49 CFR Part 665 of the Federal Code (3). One requirement is to load the bus to 2.5 times the gross load without causing permanent deformation of the structure. Another requirement is to load the bus to GVW, with one wheel on top of a 6-inch curb, and then in a 6-inch pothole. Autokinetics chose to combine these two requirements into one static proof load test, and to apply an additional margin of safety. The resulting load case applies a distributed load of 3.5 times the gross load to the floor of the bus, while supporting the vehicle on only the left-front and right-rear wheels. A roof-crush load case was also defined. This was a distributed load equal to 1.5 times the curb weight of the bus applied to the roof panel.
Analysis Results - The results of the proof load with twist load case are shown in Figure 15. This plot shows the deformed geometry (highly exaggerated) and von Mises stress in pounds per square inch. The stresses do not even approach the yield stress of Nitronic 30, and therefore no permanent deformation will result. The maximum elastic displacement is on the order of 0.5 inches. The stresses for this load case are below the $70 \mathrm{ksi}$ endurance limit for Nitronic 30 (annealed), and therefore indicate good durability performance for the bus structure.

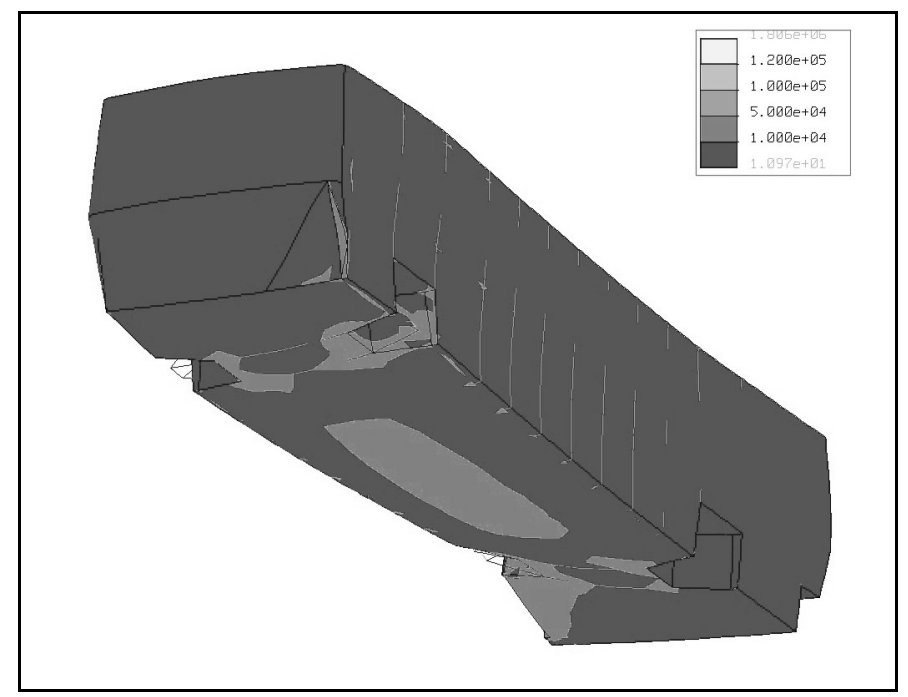

Figure 15 - Static proof load - 3.5 times gross load

The roof crush load case is shown in Figure 16. Once again, the stresses are well below yield. This is to be expected, since the roof was designed to be unusually strong and stiff, so that it can support additional components such as HVAC, and fuel cylinders.

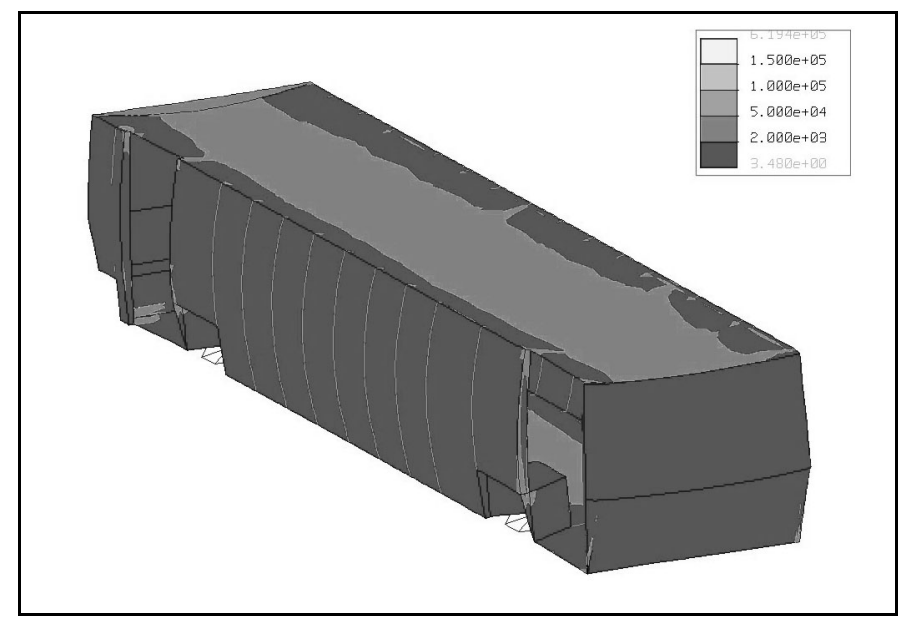

Figure 16 - Roof crush load - 1.5 times curb weight

The natural frequencies of the bus structure are presented in the following list. These frequencies are unusually high for a bus. They are even higher than many passenger cars. With the lowest frequency above $20 \mathrm{~Hz}$, the $\mathrm{NVH}$ qualities of the bus should be a significant improvement over older bus designs. 
- SEAT MODE

- $1^{\text {ST }}$ STRUCTURE MODE

- $2^{\mathrm{ND}}$ STRUCTURE MODE

$20.3 \mathrm{~Hz}$

- $1^{\text {st }}$ GLOBAL tORSION

$26.7 \mathrm{~Hz}$

$27.4 \mathrm{~Hz}$

- ROOF, FLOOR, \& SIDES

$29.1 \mathrm{~Hz}$

- $\quad 1^{\mathrm{sT}}$ GLOBAL BENDING

$30.1 \mathrm{~Hz}$

The $1^{\text {st }}$ structure mode $(20.3 \mathrm{~Hz})$ is a bit unusual in that it is neither a bending or torsion mode. It can be described as a matchboxing of the center portion of the bus structure. The added compliance of the door openings is a major contributor to this mode. A mode shape plot with strain energy is shown in Figure 17.

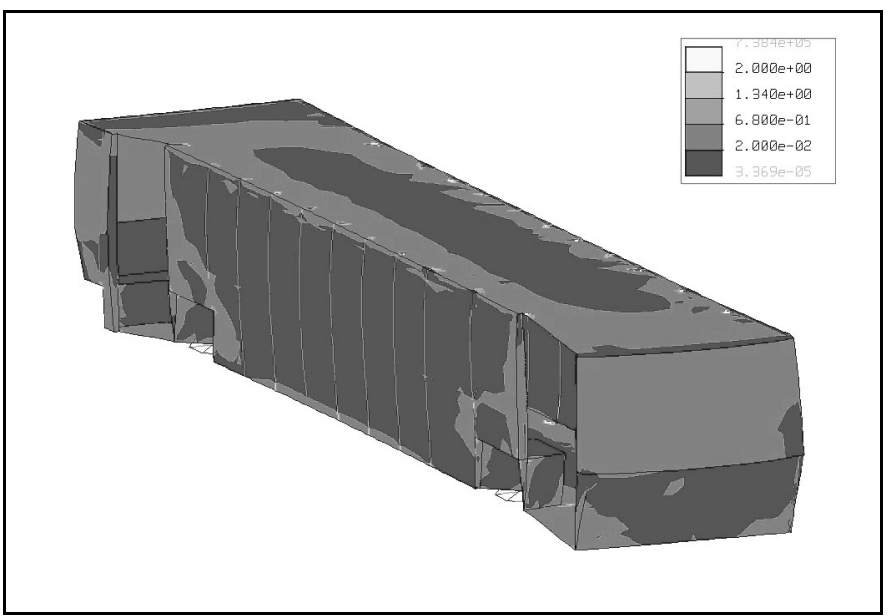

Figure $17-1^{\text {st }}$ Structure mode at $20.3 \mathrm{~Hz}$

The $2^{\text {nd }}$ structure mode is a variation of the $1^{\text {st }}$ mode, but mainly involving the flexing of the rear door opening. The first torsion mode occurs at $26.7 \mathrm{~Hz}$ and is shown in Figure 18.

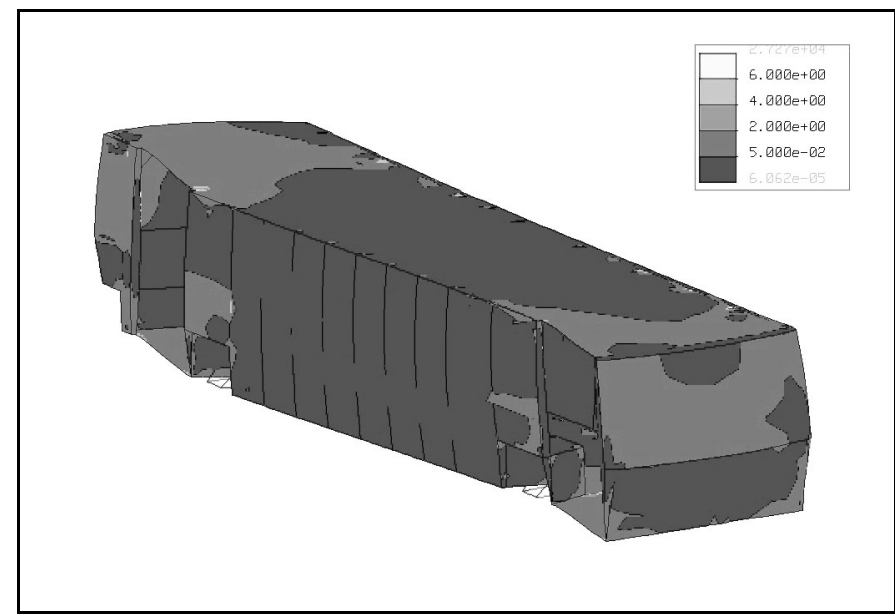

Figure 18 - Torsion mode

FLOOR MODEL - The floor and roof sandwich panels presented a modeling challenge. In reality, the panels are composed of two outer face sheets and a corrugated inner core. The three layers are spot-welded together.
To represent the detailed geometry of these panels over the full area of the bus floor and roof would require an enormous number of elements. Instead the floor and roof were modeled using multi-ply composite elements. The multi-ply element, as provided in Pro-MECHANICA, is a single thickness shell element that allows property data to be input in a multi-layered format. The outer skins were given standard material properties for stainless steel. The core layer was given a reduced density and elastic modulus to represent the properties of the corrugated core. To confirm the accuracy of this approach, a detailed shell model of a section of the floor was built. The floor section was one half of the full bus width by 6.25 inches, measured along the fore/aft axis of the bus. This model included the actual geometry of the corrugations, as well as the spot-welds. The sample floor section was constrained to represent a full-width, infinitely long, simply supported floor panel. The natural frequency of the detailed model was compared to a similar model built using multi-ply composite elements. The results of the detailed model are shown in Figure 19. This plot shows the deformed mode shape of the first natural frequency at $34.5 \mathrm{~Hz}$. The contours show element total strain energy.

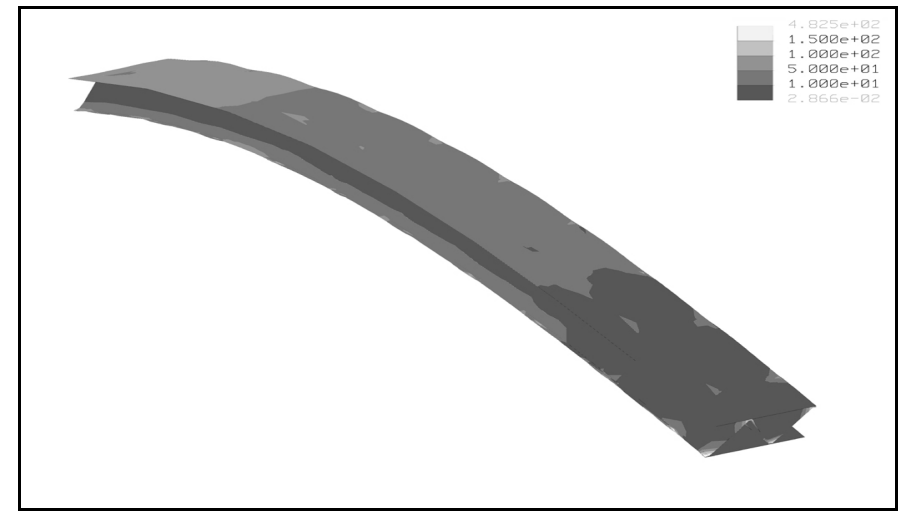

Figure 19 - Detailed model of floor section

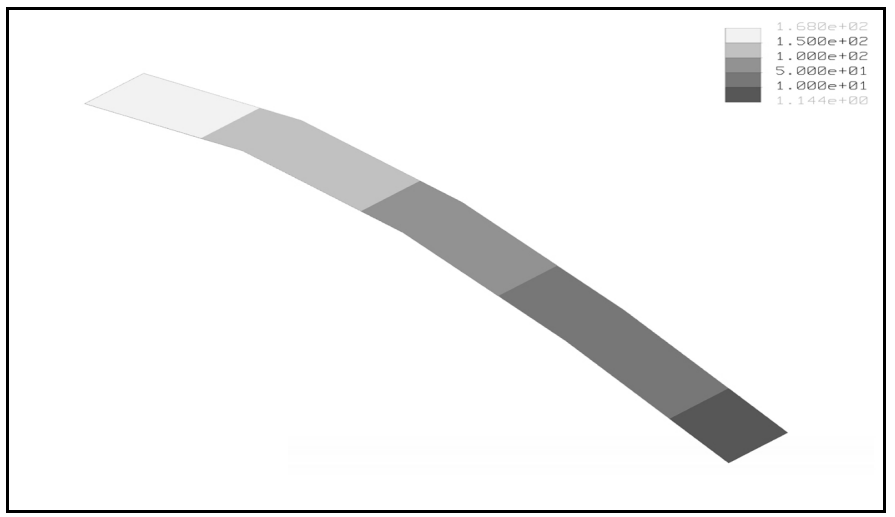

Figure 20 - Model of floor section using multi-ply elements

Figure 20 shows the simplified model under the same conditions. The first mode of this model is at $34.8 \mathrm{~Hz}$. This is a remarkably good level of agreement considering the large difference in model geometries. 
The detailed floor model was also used to evaluate the stresses around the widely spaced spot-welds. With a static loading equal to 3.5 times the gross load, the von Mises stresses in the vicinity of the spot-welds was well below the yield stress of tensilized Nitronic 30 .

WINDOW MODEL - Since the full bus model indicated that the windows have a significant impact on the global natural frequencies of the structure, a separate study of window mounting stiffness was conducted. In an actual bus, window configurations typically include various combinations of fixed glass, sliding windows, and emergency exit windows. In order to study the sensitivity of global frequencies to the shear stiffness of the window installation, it was assumed that all windows were bonded to the bus structure using a compliant urethane adhesive. To avoid the complexity of modeling the adhesive layer in the full bus model, the material properties of the window glass were modified to simulate the effect of the compliant adhesive. A model was built of a single window with the adhesive represented as a row of shell elements around the periphery of the glass and perpendicular to it. A pure shear load case was applied to the adhesive, along the edge that would be bonded to the bus structure. The shear deformation of the glass/adhesive combination was evaluated relative to a window with no adhesive, but with modified material properties. It was determined that a reduction in the inplane shear modulus of the glass by a factor of 50 resulted in a good approximation of the overall stiffness of a bonded window.

SEAT MODEL - The cantilever seat concept utilizes a pair of unique butterfly brackets to connect the seat beams to the side pillars. To investigate the feasibility of this approach, a model was built of a forward seat beam, a side pillar, and an attachment bracket. This was a shell model, with the spot-welds and fasteners represented by short, specialized beam elements.

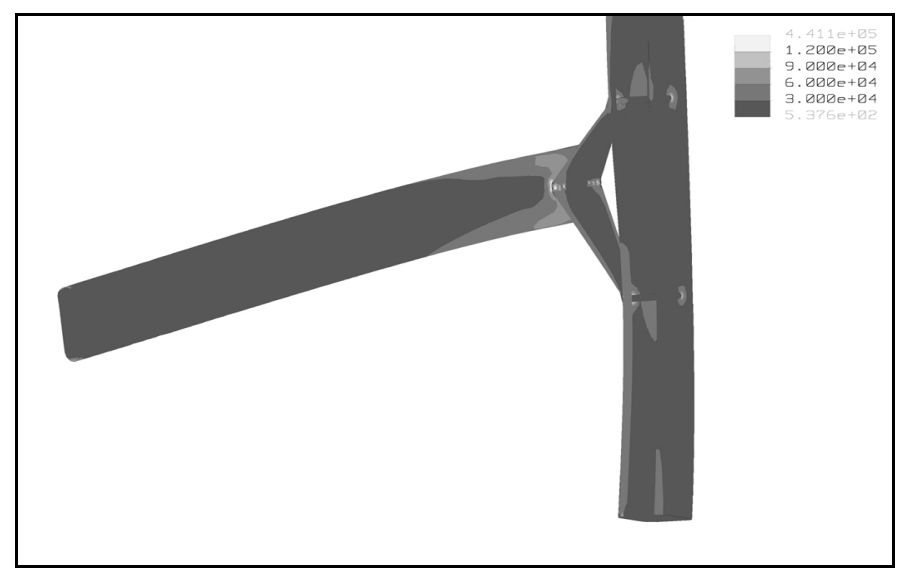

Figure 21 - Forward seat beam subjected to $1500 \mathrm{lb}$ proof load

A proof load of $1500 \mathrm{lbs}$ was uniformly distributed along the forward seat beam. This load is equivalent to two $250 \mathrm{lb}$ persons sitting on the front edge of the seat while being subjected to a $3 \mathrm{~g}$ bump. The deformed stress plot shown in Figure 21 indicates little or no yielding of the material.

1/5 SCALE PLASTIC MODEL - A 1/5 scale model of the bus structure was constructed using vacuum-formed PVC plastic (see Figure 22). Spot-welds were simulated using ultrasonic welding. The purpose of this model was to evaluate construction details and assembly procedure. It has also served as a valuable visual aid.

Ordinarily, scaling laws could be applied to such a model in order to predict full-scale natural frequencies. Unfortunately, it was not possible to obtain PVC material in the correct $1 / 5$ scale thicknesses. Dynamic shaker tests were conducted, and the results generally confirm the finite element analysis results, but because of the uncertainty, the results will not be presented here.

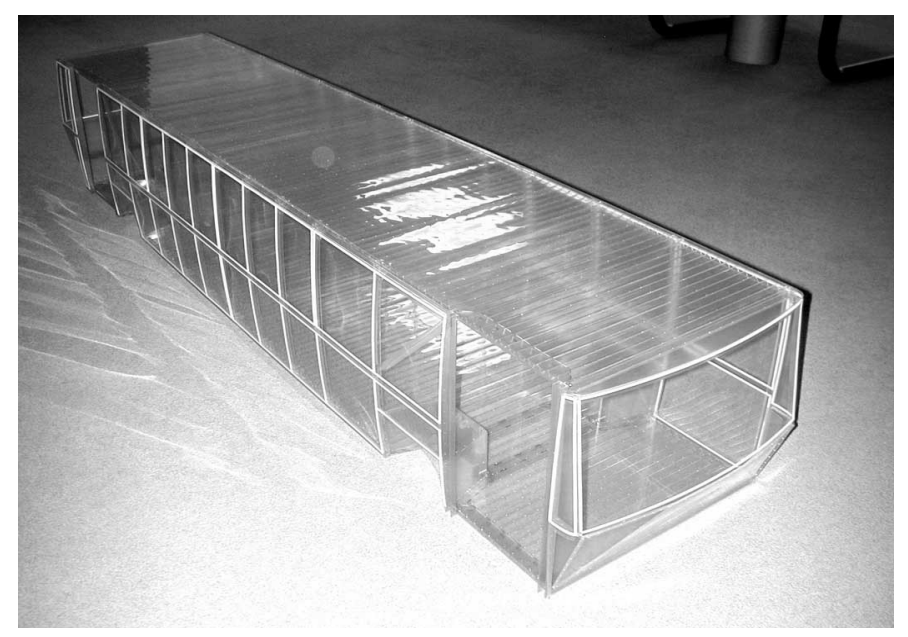

Figure 22 - 1/5 Scale plastic model 


\section{RESULTS}

MASS REDUCTION - The result of the design and analysis presented above is an estimated curb weight of $9600 \mathrm{lbs}$. This represents a $64 \%$ reduction in mass compared with a conventional bus. The lower curb weight allows for a $42 \%$ increase in payload without exceeding legal axle limits. In other words, $40 \%$ more passengers can be carried on the same size bus. These results are illustrated graphically in Figure 23.

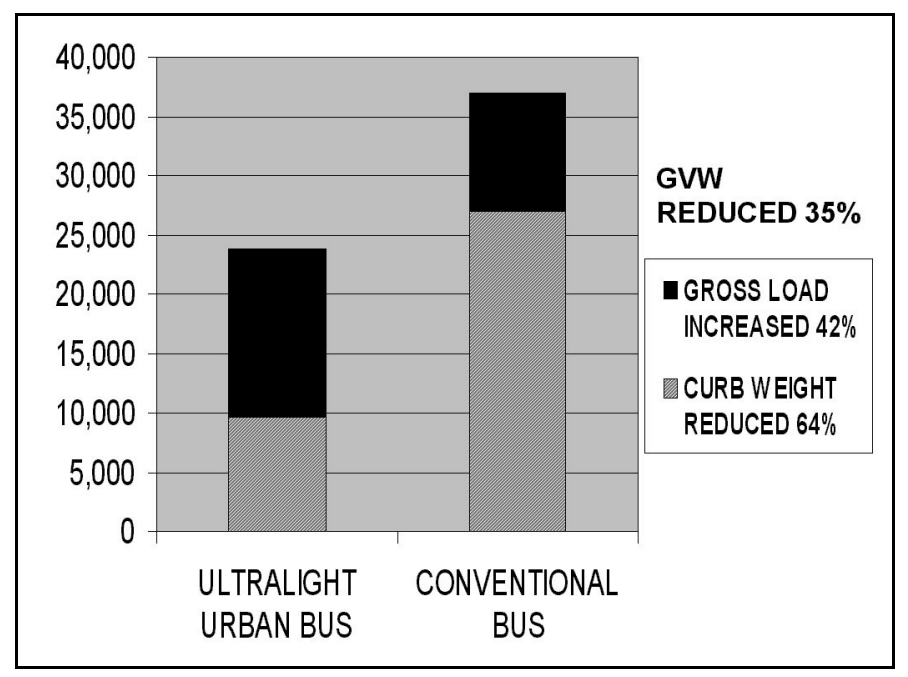

Figure 23 - Mass reduction

COST REDUCTION - While the entire bus was designed for cost-effective manufacture, there is not yet a specific cost analysis to support a claim of actual cost reduction. However, certain logical statements can be made:

- The cost of Nitronic 30 is slightly less than 304 stainless (used on other bus designs).

- Less material is required due to the reduced mass of the structure.

- The scrap rate for the roll-forming process is much less than for the stamping process used on some other buses.

- The labor content for assembly is very low.

- The tooling investment is very low.

These factors all contribute to lowering the cost of manufacture relative to existing bus designs.

\section{CONCLUSION}

The combination of ultra-high strength stainless steel with a fresh design approach offers the potential to drastically reduce the curb mass of a transit bus. This, in turn, enables a significant increase in the passenger capacity of the bus without exceeding legal axle limits. The benefits, in terms of fuel economy per passenger mile, have not yet been demonstrated, but should be considerable.
If the manufacturing costs can be reduced as expected, then the major obstacle to introduction of fuel-efficient advanced technology transit buses will be overcome.

\section{REFERENCES}

1. US Department of Transportation "Management Advisory Memorandum on Advanced Technology Transit Bus Project" R3-FT-7-001 12/18/96

2. American Public Transit Association "Standard Bus Procurement Guidelines"

3. US Department of Transportation, Federal Transit Administration "49 CFR Part 665 Bus Testing"

4. AK Steel Nitronic 30 Product Data Bulletin

\section{CONTACT}

\section{J. Bruce Emmons jbemmons@autokinetics.com}

\section{DEFINITIONS, ACRONYMS, ABBREVIATIONS}

OHVT: Office of Heavy Vehicle Technologies

NVH: Noise, Vibration, and Harshness

APTA: American Public Transportation Association

ATTB: Advanced Technology Transit Bus

MIG: Metal Inert Gas welding 